\title{
Nosocomial infections in a neonatal intensive care unit in south-western Saudi Arabia
}

A.A. Mahfouz, ${ }^{1,2}$ T.A. Al-Azraqi, ${ }^{1,3}$ F.I. Abbag, ${ }^{4}$ M.N. Al-Gamal, ${ }^{1,5}$ S.Seef ${ }^{1,5}$ and C.S. Bello ${ }^{1,6}$

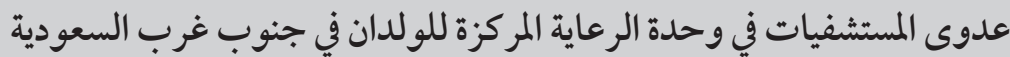

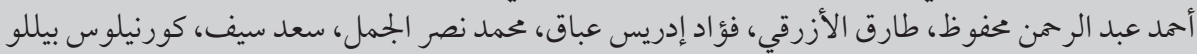

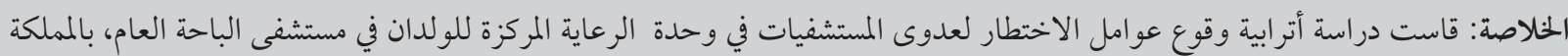

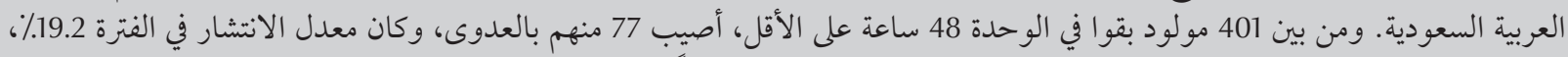

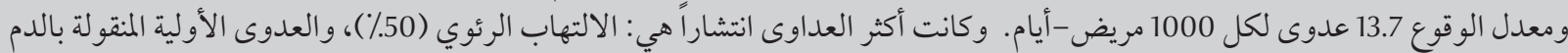

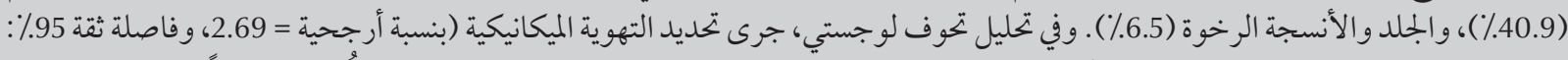

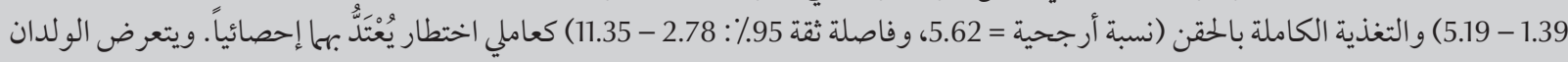

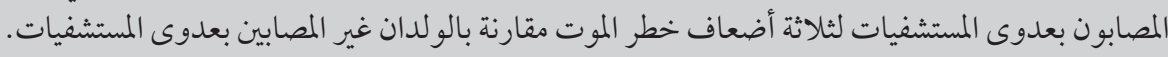

ABSTRACT A cohort study measured the occurrence and risk factors of nosocomial infections in the neonatal intensive care unit of Abha general hospital, Saudi Arabia. Of 401 neonates who stayed at least 48 hours in the unit, 77 developed infections, a period prevalence of $19.2 \%$ and an incidence of 13.7 infections per 1000 patientdays. The most frequent infections were: pneumonia (50.0\%), primary bloodstream $(40.9 \%)$ and skin and soft tissues (6.5\%). In logistic regression analysis, mechanical ventilation $(\mathrm{OR}=2.69,95 \% \mathrm{Cl}: 1.39-5.19)$ and total parenteral nutrition $(\mathrm{OR}=5.62,95 \% \mathrm{Cl}: 2.78-11.35)$ were identified as significant risk factors. Neonates suffering from nosocomial infections had more than 3 times the risk of dying compared to neonates free of infection.

Infections nosocomiales dans un service de soins intensifs néonatals du sud-ouest de l'Arabie saoudite

RÉSUMÉ Une étude de cohorte a mesuré la fréquence des infections nosocomiales et leurs facteurs de risque dans le service de soins intensifs néonatals de l'hôpital général d'Abha (Arabie saoudite). Sur 401 nouveau-nés ayant séjourné au moins 48 heures dans le service, 77 ont contracté des infections, avec une prévalence de $19,2 \%$ au cours de la période et une incidence de 13,7 infections pour 1000 jours-patient. Les infections les plus fréquentes étaient la pneumonie $(50,0 \%)$, les bactériémies primaires $(40,9 \%)$ et les infections de la peau et des tissus mous (6,5\%). Dans I'analyse de régression logistique, la ventilation artificielle ( $O R=2,69$, IC $95 \%: 1,39$ $5,19)$ et l'alimentation parentérale totale $(O R=5,62$, IC $95 \%: 2,78-11,35)$ ont été identifiées comme facteurs de risque significatifs. Les nouveau-nés souffrant d'infections nosocomiales avaient plus de 3 fois plus de risques de mourir que les autres.

${ }^{7}$ Asir Regional Committee for Nosocomial Infection Control; ${ }^{5}$ Asir General Directorate of Health Affairs, Asir, Saudi Arabia.

${ }^{2}$ Department of Family and Community Medicine; ${ }^{3}$ Department of Internal Medicine; ${ }^{4}$ Department of Child Health; ${ }^{6}$ Department of Clinical Microbiology, College of Medicine, King Khalid University, Asir, Saudi Arabia (Correspondence to A.A. Mahfouz: mahfouz2005@gmail.com). Received: 04/07/07; accepted: 02/09/07 


\section{Introduction}

Neonatal deaths account for over a third of the global burden of child mortality [1]. In many developing countries neonatal mortality rates (deaths in the first 28 days of life) are as high as $40-50$ per 1000 live births [2,3], with infections being the major cause of death $[4,5]$. Unfortunately, hospitals in developing countries are at high risk of infection transmission, and improvements in neonatal outcomes are subverted by hospital-acquired infections and their associated morbidity, mortality and cost [6-9]. These infections can be attributed to lack of knowledge and training about basic infection control processes, coupled with inadequate infrastructure, systems of care and resources. This has serious consequences when devices such as intravenous catheters and ventilators are introduced without sufficient attention to the substantial risk of infection they entail [10-12].

The Asir region (population of 1200000 ) is located in the south-west of Saudi Arabia covering an area of more than $80000 \mathrm{~km}^{2}$. Primary health care (PHC) services in Abha health district, the capital of Asir, are provided through a widespread network of 36 urban and rural health centres, providing services to a population of 129465 . Each PHC centre has well-defined catchment area and population. Secondary care is provided at Abha general hospital where almost all deliveries are performed.

Our objective was to study the occurrence and risk factors of nosocomial infections (NIs) at Abhageneral hospital neonatal intensive care unit (NICU).

\section{Methods}

Abha general hospital is a 100-bed general hospital with an average of 300 births a month and a 15-bed NICU. The NICU consists of 4 rooms with a capacity of 15-30 hospital-born neonates. The NICU was staffed with 22 registered nurses/nurse assistants, 5 per shift, a ratio of nurses/nurse assistants to NICU patients of 1:5. The registered nurses supervised the team and were directly responsible for the care of the most severely ill patients. The medical staff included neonatologists, 1 on call every 24 hours and 4 who worked on a daily basis. One of these neonatologists was responsible for the NICU for 24-hour periods. A chief physician and a registered nurse were responsible for the neonatal unit as a whole. Consultant support was available when necessary fromnearby Asircentral tertiary hospital. A physical therapist was also present in the unit for 8-hour periods. There were 5 hand-washing sinks in the NICU, 1 at the entrance, 1 at the nurse's station, and 1 sink for each $10 \mathrm{~m}^{2}$. Six conventional ventilators provided assisted ventilation on a conventional basis.

A cohort of all neonates attending Abha NICU from 1 January 2004 to 31 March 2005 and who remained at least 48 hours were followed up and evaluated. All neonates were examined at the time of admission and the following information was recorded: gestational age, birth weight, Apgar score at 1 and 5 minutes, maternal predisposing factors, mode of delivery, length of stay and exposure to vascular catheter, endotracheal intubation, mechanical ventilation, antibiotic therapy and total parenteral nutrition. Surveillance for development of NI, death and transfer to other units was conducted 2-3 times a week and recorded using a manual spreadsheet. The outcome variable was acquisition of a NI, assessed and classified using Centers for Disease Control and Prevention definitions [13].

Data were analysed using SPSS, version 12.0. Univariate analysis methods were used at $5 \%$ level of significance. Multivariate logistic regression analysis was used to identify potential risk factors.

\section{Results}

During the study period, 401 neonates were admitted to Abha NICU and remained at least 48 hours. There were 233 males (58.1\%) and 168 females (41.9\%). The 5 primary reasons for admission to the NICU were preterm and hyaline membrane disease (50.5\%), transient tachypnoea of newborn (8.2\%), meconium asphyxia syndrome (6.2\%) and birth asphyxia (4.1\%). There were 54 neonates with a congenital anomaly (13.7\%). Half the neonates were born through unassisted vaginal delivery (50.3\%) and half by caesarean section $(47.7 \%)$ or instrumental delivery $(2.0 \%)$. The mean length of stay was 14.0 (SD 19.5) days and median 8 days.

In all, 77 neonates developed a NI, a period prevalence of $19.2 \%$ and incidence of 13.7 NIs per 1000 patient-days observation. The commonest sites of infection were: lungs (pneumonia) (50.0\%), blood (primary bloodstream infection) (40.9\%), skin and soft tissues (6.5\%) and urinary tract $(2.6 \%)$. Table 1 shows the

\begin{tabular}{lcc}
\hline $\begin{array}{l}\text { Table 1 Distribution of isolated pathogens related to nosocomial infections in } \\
\text { Abha neonatal intensive care unit ( } \boldsymbol{n}=\mathbf{7 7} \text { infants) }\end{array}$ & No. of infants & $\%$ \\
\hline Isolated organisms & 18 & 23.4 \\
Coagulase-negative Staphylococcus spp. & 17 & 22.1 \\
Klebsiella spp. & 16 & 20.8 \\
Enterobacter cloacae & 8 & 10.4 \\
Methicillin-resistant Staphylococcus aureus & 1 & 1.3 \\
Group B Streptococcus & 5 & 6.5 \\
Serratia spp. & 6 & 7.8 \\
Escherichia coli & 1 & 1.3 \\
Staphylococcus aureus & 5 & 6.5 \\
Other Gram-negative bacilli & & \\
\hline
\end{tabular}


distribution of isolated pathogens related to NIs. The most frequently isolated organisms were coagulase-negative Staphylococcus spp. (23.4\%), Klebsiella spp. (22.1\%) and Enterobacter cloacae (20.8\%).

Using logistic regression analysis to identify risk factors associated with NIs (Table 2) the following significant risk factors were identified: mechanical ventilation (adjusted $\mathrm{OR}=2.69,95 \%$ CI: $1.39-5.19)$ and total parenteral nutrition (adjusted OR $=5.62,95 \% \mathrm{CI}$ :
2.78-11.35). Sex, birth weight, method of delivery, gestational age and intravenous line were not associated with development of NIs.

During the study period 87 neonates $\operatorname{died}(21.7 \%)$. Mortality amongneonates suffering from NIs (40.3\%) was significantly higher compared with neonates free from NIs $(17.3 \%)\left(\chi^{2}=19.33, P<\right.$ $0.05)$. Neonates suffering from NIs had 3 times the risk of dying compared with neonates free from NIs (crude OR = $3.23,95 \% \mathrm{CI}=1.80-5.70)$.

\section{Discussion}

Babies are born without an endogenous microbial flora and rapidly become colonized with microbes encountered in the maternal genital tract and their immediate postnatal environment [14]. Since their immature immune systems are unable to provide a robust defence against virulent pathogens, neonates are at high risk of developing invasive infections if exposed to pathogenic microorganisms. Premature neonates

\begin{tabular}{|c|c|c|c|c|}
\hline \multirow[t]{2}{*}{ Variable } & \multicolumn{2}{|c|}{ Nosocomial infections } & \multirow[t]{2}{*}{ Adjusted OR } & \multirow[t]{2}{*}{$95 \% \mathrm{Cl}$} \\
\hline & No. & $\%$ & & \\
\hline \multicolumn{5}{|l|}{ Sex } \\
\hline Male & 44 & 18.9 & 0.80 & $0.45-1.42$ \\
\hline Female & 33 & 19.9 & & \\
\hline \multicolumn{5}{|c|}{ Mode of delivery } \\
\hline Caesarean & 39 & 19.5 & 1.02 & $0.58-1.80$ \\
\hline Vaginal & 38 & 19.0 & & \\
\hline \multicolumn{5}{|c|}{ Presence of congenital anomalies } \\
\hline Yes & 9 & 18.0 & 1.06 & $0.45-2.46$ \\
\hline No & 68 & 16.8 & & \\
\hline \multicolumn{5}{|c|}{ Low birth weight $(<1500 \mathrm{~g})$} \\
\hline Yes & 25 & 27.8 & 0.68 & $0.43-1.17$ \\
\hline No & 52 & 16.7 & & \\
\hline \multicolumn{5}{|c|}{ Gestational age } \\
\hline Preterm & 62 & 27.4 & 0.58 & $0.32-1.03$ \\
\hline Term & 15 & 8.6 & & \\
\hline \multicolumn{5}{|c|}{ Mechanical ventilation } \\
\hline Yes & 39 & 35.8 & $2.69^{*}$ & $1.39-5.19$ \\
\hline No & 38 & 13.0 & & \\
\hline \multicolumn{5}{|c|}{ Intravenous line } \\
\hline Yes & 70 & 18.1 & 0.07 & $0.18-2.52$ \\
\hline No & 7 & 50.0 & & \\
\hline \multicolumn{5}{|c|}{ Total parenteral nutrition } \\
\hline Yes & 31 & 57.4 & $5.62^{*}$ & $2.78-11.35$ \\
\hline No & 46 & 13.3 & & \\
\hline \multicolumn{5}{|c|}{ Endotracheal intubation } \\
\hline Yes & 2 & 33.3 & 0.96 & $0.14-6.84$ \\
\hline No & 75 & 19.0 & & \\
\hline
\end{tabular}

*P $<0.05$

$O R=$ odds ratio; $C I=$ confidence interval. 
are at especially high risk of infection because of their lack of protective maternal antibodies, underdeveloped innate immunity and their fragile, easily damaged skin. However, while the newborn intrinsically faces an increased risk of infection, failures at critical points in the system of care can greatly increase this risk. The rapid development of medical technology has enhanced our ability to improve the quality and length of life of neonates, particularly infants born with congenital defects or extreme prematurity. This growing population of fragile patients is often dependent for survival on therapeutic interventions that are associated with complications of infections that can result in neonatal morbidity and mortality $[15,16]$.

The present study showed a relatively high prevalence of NIs in Abha NICU of $19.2 \%$ with an incidence rate of 13.7 infections per 1000 patient-days observation. Previous studies have documented widely varying infection rates between individual institutions. A prospective multicentre study conducted by the European Study Group found an infection rate of $7 \%$ in 7 NICUs [17]. The USA national point prevalence survey, a collaborative study in 29 hospitals representing 19 states, found a NICU infection rate of 11.4\% [18]. In Spain a study found an incidence rate of $1.6 \mathrm{NIs}$ per 100 patients-day observation in the NICU [19]. In developing countries, investigators in Brazil and Indonesia have reported rates of hospital-acquired infections to be as high as $51 \%-52 \%$ among all NICU admissions $[12,16]$. Although the Centers for Disease
Control and Prevention definitions are usually used in these studies, it may be difficult to make direct comparisons with these data because of inconsistencies in surveillance or study methods, such as intensity of surveillance, prospective versus retrospective data collection, infection detection methods and the populations included.

Bacteraemia, pneumonia, urinary tract infections and sensory organ infections are the most common NIs reported in the literature, with $40 \%$ to $70 \%$ for bacteraemia and $15 \%$ to $30 \%$ for respiratory infection $[16,19,20]$. These are in agreement with our results.

The present study showed that the most frequentlyisolated organisms were coagulase-negative Staphylococcus spp., Klebsiella spp. and Ent. cloacae. In developing countries Gram-negative rods are major pathogens of NIs in NICUs. Gram-negative rods were isolated from at least $60 \%$ of positive blood cultures in developing regions of the world [16]. K. pneumoniae is the major pathogen, responsible for $16 \%-28 \%$ of bloodculture-confirmed sepsis in different regions of the world. Africa and South Asia also have high rates of Sta. aureus infections, whereas Latin America, SouthEast Asia and the Middle East have high reported rates of coagulase-negative staphylococcal infections that might be due to their adoption of sophisticated tertiary neonatal care with a high rate of invasive device use [16].

Neonates in Abha NICU on mechanical ventilation had significantly 2.7 times higher risk of developing NIs compared with other neonates.
Similarly, in Riyadh, Saudi Arabia the mean ventilator-associated pneumonia rate in the paediatric ICU was 8.87 per 1000 ventilation-days with a ventilation utilization rate of $47 \%$ [21].

Neonates in Abha NICU on total parenteral nutrition had a significantly 5.6 times greater risk of developing NIs compared with other neonates. Similarly, in Riyadh, a study showed that in paediatric ICUs, patients who had total parenteral nutrition infused through the line had 8.6 times greater risk of developing NIs [22]. This may be due to the severity of illness or a deficiency in adhering to parenteral fluid infusion guidelines. Standard infectioncontrol practices - hand hygiene, isolation, aseptic techniques, cleaning and disinfection or sterilization of reused equipment and elimination of point sources of contamination - minimize many such hazards. Alcohol-based antiseptics for hand hygiene are an appealing innovation because of their efficacy in reducing hand contamination and their ease of use, especially when sinks and supplies for hand-washing are limited [23].

The results of this study will assist in developing intervention strategies for the prevention of NIs in NICUs in the region. Interventions should target the use of total parenteral nutrition (indications, preparation, storage, administration and time of use) and mechanical ventilation. More continuing medical education programmes are needed for the health care team to improve their competence.

\section{References}

1. Lawn JE et al. Why are 4 million newborn babies dying each year? Lancet, 2004, 364:399-401.

2. Saving Newborn Lives. The state of the world's newborns: a report from Saving Newborn Lives. Washington DC, Save the Children, 2001.

3. Hyder AA, Wali SA, McGuckin J. The burden of disease from neonatal mortality: a review of South Asia and Sub-Saharan
Africa. British journal of obstetrics and gynaecology, 2003, 110:894-901.

4. Mother-baby package: a road map for implementation in countries. Geneva, World Health Organization, 1993.

5. Stoll BJ. Neonatal infections: a global perspective. In: Remington JS, Klein JO, eds. Infectious diseases of the fetus and newborn infant, 5th ed. Philadelphia, WB Saunders, 2001:139-68. 
6. Nejjari $\mathrm{N}$ et al. Infections nosocomiales a Acinetobacter experience du service de neonatologie de Casablanca. [Nosocomial infections caused by Acinetobacter: experience in a neonatal care unit in Casablanca.] La Tunisie médicale, 2003, 81:121-5.

7. Yalcin AN. Socioeconomic burden of nosocomial infections. Indian journal of medical science, 2003, 57:450-6.

8. Raza MW et al. Developing countries have their own characteristic problems with infection control. Journal of hospital infection, 2004, 57:294-9.

9. Richards $\mathrm{C}$ et al. Klebsiella pneumoniae bloodstream infections among neonates in a high-risk nursery in Cali, Colombia. Infection control and hospital epidemiology, 2004, 25:221-5.

10. Ho J. Late onset infection in very low birth weight infants in Malaysian level 3 neonatal nurseries. Pediatric infectious disease journal, 2001, 20:557-60.

11. Martinez-Aguilar G et al. Outbreak of nosocomial sepsis and pneumonia in a newborn intensive care unit by multiresistant extended-spectrum beta-lactamase producing Klebsiella pneumoniae: high impact on mortality. Infection control and hospital epidemiology, 2001, 22:725-8.

12. Nagata E, Brito AS, Matsuo T. Nosocomial infections in a neonatal intensive care unit: incidence and risk factors. American journal of infection, 2002, 30:26-31.

13. Garner JS et al. CDC definitions for nosocomial infections. American journal of infection, 1988, 16:128-40.

14. Harris J, Goldmann D. Infections acquired in the nursery: epidemiology and control. In: Remington JS, Klein JO, eds. Infectious diseases of the fetus, newborn and infants, 5th ed. Philadelphia, WB Saunders, 2001:1371-418.
15. Klein JO. Bacterial sepsis and meningitis. In: Remington JS, Klein JO, eds. Infectious diseases of the fetus, newborn and infants, 5th ed. Philadelphia, WB Saunders, 2001:943-84.

16. Zaidi A et al. Hospital-acquired neonatal infections in developing countries. Lancet, 2005, 365:1175-88.

17. Raymond J, Aujard Y. Nosocomial infections in pediatric patients: a European, multicenter prospective study. European Study Group. Infection control and hospital epidemiology, 2000, 21:260-3.

18. Sohn A et al. Prevalence of nosocomial infections in neonatal intensive care unit patients: results from the first national pointprevalence survey. Journal of pediatrics, 2001, 139(6):821-7.

19. Urrea $\mathrm{M}$ et al. A prospective incidence study of nosocomial infections in a neonatal care unit. American journal of infection, 2003, 31(8):505-7.

20. Kilani RA, Basamad M. Pattern of proven bacterial sepsis in a neonatal intensive care unit in Riyadh-Saudi Arabia: a 2-year analysis. Le journal médical libanais, 2000, 48(2):77-83.

21. Almuneef $\mathrm{M}$ et al. Ventilator-associated pneumonia in a pediatric intensive care unit in Saudi Arabia: a 30-month prospective surveillance. Infection control and hospital epidemiology, 2004, 25(9):753-8.

22. Almuneef $M$ et al. Rate, risk factors and outcomes of catheter related blood stream infection in a pediatric intensive care unit in Saudi Arabia. Journal of hospital infection, 2006, 62(2):207-9.

23. Brown SM et al. Use of an alcohol-based hand rub and quality improvement interventions to improve hand hygiene in a Russian neonatal intensive care unit. Infection control and hospital epidemiology, 2003, 24:172-9.

\section{Note from the Editor}

We wish to draw the kind attention of our potential authors to the importance of applying the editorial requirements of EMHJ when preparing their manuscripts for submission for publication. These provisions can be seen in the Guidelines for Authors, which are available online at http:/ / www.emro.who.int/emhj.htm, and are published at the end of the first issue of each volume. We regret that we are unable to consider papers that do not conform to the Guidelines. 